\title{
Anselmo Peres Alós - Leituras a contrapelo da narrativa brasileira: redes intertextuais de gênero, raça e sexualidade
}

Santa Maria: PPGL/UFSM, 2017

Camila Marchesan Cargnelutti*

Em tempos conturbados social e politicamente, refletir sobre categorias que historicamente foram consideradas representativas da diferença e bases de argumentos discriminatórios, tais como gênero, raça e sexualidade, torna-se, mais que uma forma de romper o silenciamento imposto a essas vozes, um ato de resistência frente a esses acirramentos extremistas ainda pautados em discursos conservadores, patriarcais e opressivos. Com análises e reflexões sobre um corpus bastante diverso, Leituras a contrapelo da narrativa brasileira: redes intertextuais de gênero, raça e sexualidade, ${ }^{1}$ publicado em 2017 por Anselmo Peres Alós, ${ }^{2}$ promove o fortalecimento desse debate ao apresentar um conjunto de estudos que, se em um primeiro momento pode parecer aleatório pela diversidade de textos, dialoga diretamente com as categorias da diferença acima citadas.

Escritos entre 2001 e 2014, os textos publicados nesse volume são representativos da própria trajetória de pesquisa acadêmica de Alós, marcada por incursões em temas como subalternidade, diferença, raça, etnia, gênero e desejo sexual. Composto por onze capítulos, Leituras a contrapelo da narrativa brasileira... tem como fio condutor questões relacionadas à alteridade em obras literárias, aliadas às discussões sobre o processo histórico de silenciamento e de transformação dos sujeitos considerados como alteridade em "cidadãos de segunda categoria", particularmente em países latino-americanos, um dos espaços principais do estudo de Alós.

Dentre os capítulos da obra do pesquisador, "Literatura e intervenção política na América Latina: Rigoberta Menchú e Carolina Maria de Jesus" destaca-se particularmente ao trazer, de maneira comparativa, uma análise de duas obras literárias de testemunho de autoria feminina: Me llamo Rigoberta Menchú y así me nació la consciencia, da guatemalteca Rigoberta Menchú em parceria com Elizabeth Burgos-Debray, e Quarto de despejo: diário de uma favelada, da brasileira Carolina Maria de Jesus, publicado a partir da intervenção do jornalista Audálio Dantas. A comparação entre as obras busca evidenciar como esses artefatos culturais, escritos por mulheres (uma pobre, negra e favelada, no caso do Brasil, e uma descendente de indígenas, no caso da Guatemala), interferem nas modalidades de se pensar a instituição literária na América Latina. Conforme explica Alós, esse processo passa por dois problemas relacionados a um mesmo termo (ainda que com significados diferentes): gênero.

O primeiro problema refere-se ao silenciamento imposto às mulheres ao longo da escritura das literaturas latino-americanas - diretamente relacionado a uma cultura e a uma sociedade com bases falocêntricas, na qual a construção de identidades assumidas como femininas ou masculinas passa invariavelmente por relações de poder (Scott, 1990), e essas relações manifestam-se, também, na crítica e na história literária. O segundo problema diz respeito aos gêneros literários, uma vez que as mulheres, tradicionalmente, se dedicaram a escrever na forma de gêneros considerados "menores", tais como a autobiografia, a narrativa memorialista, o diário confessional e os imprompts narrativos. Esses escritos literários de mulheres eram particularmente desconsiderados quando colocados em comparação com gêneros literários "maiores", já consagrados, como a epopeia, o romance ou o soneto.

\footnotetext{
* Doutoranda em Letras na Universidade Federal de Santa Maria (UFSM), Santa Maria, RS, Brasil. (Dorcid.org/0000-0002-09365124. E-mail: camila.m.cargnelutti@gmail.com

${ }^{1} \mathrm{O}$ livro pode ser baixado gratuitamente no seguinte endereço eletrônico: https://bit.ly/2WWz32J.

${ }^{2}$ Anselmo Peres Alós também é autor de A letra, o corpo e o desejo (2013) e organizador do volume Poéticas da masculinidade em ruínas (2017). Co-organizou, com Renata de Felippe e Andrea Souto, o volume Figurações do imaginário cinematográfico na contemporaneidade (2017).
} 
No âmbito da América Latina da segunda metade do século XX, ganhou força uma forma distinta de escrita, conhecida como literatura de testemunho ou literatura de depoimento, como uma maneira de apropriação da escrita literária para expressar distintas formas de opressão de grupos subalternos, especialmente em contextos de repressão política e ideológica, como nas ditaduras latino-americanas do século XX. A literatura de testemunho, aliando intertextualmente um caráter documental à ficcionalidade (Randall, 1992), foi a forma adotada pelas escritoras analisadas nesse capítulo, expressando comprometimento com importantes questões políticas da época: Rigoberta Menchú, alinhada com a luta anticolonialista dos povos indígenas da Guatemala, e Carolina Maria de Jesus, dando voz à sua vivência como mulher, pobre, negra, catadora de papel e moradora da Favela do Canindé, em São Paulo. Conforme ressalta Alós, a obra de Carolina, na forma de testemunho, revela nitidamente a percepção da dupla opressão sofrida pela autora, tanto por seu gênero, quanto por sua raça: "ela manifesta simultaneamente consciência de que a opressão que sofre é dupla, pois está vitimada pelos imperativos patriarcais tanto quanto pelos pressupostos da opressão racial" (Alós, 2017, p. 101).

Seguindo nessa perspectiva, o capítulo seguinte - "Histórias entrelaçadas: redes intertextuais em narrativas afro-brasileiras" - promove um diálogo ímpar com o anterior, na medida em que continua com o olhar voltado à obra de Carolina Maria de Jesus, em comparação com outras duas escritoras brasileiras (Conceição Evaristo e Maria Firmina dos Reis). Estabelecendo um diálogo por três diferentes séculos da história literária nacional, sob a perspectiva de escritoras afro-brasileiras, esse capítulo também é construído a partir das inter-relações entre gênero, raça e classe nas produções literárias dessas autoras. As obras trazem reflexões acerca de questões sociais e políticas, como as consequências geradas por uma tradição patriarcal e escravocrata, relacionada aos processos de pauperização, estigmatização e subalternização social das populações afro-brasileiras.

No interior do sistema literário nacional e latino-americano, os escritos abordados nesse conjunto de estudos promovem uma espécie de desestabilização, na medida em que desconstroem estruturas que sustentam as formas de pensar a cultura e a literatura ao longo dos séculos. Para que isso aconteça, torna-se necessário articular conhecimentos de categorias de diferentes campos do conhecimento, como a filosofia, a psicologia, a história, a antropologia, a sociologia, com uma perspectiva interdisciplinar e tendo em vista uma concepção de literatura que a compreenda como representação estético-cultural, intrinsecamente ligada à política e aos contextos sócio-históricos em que se produz. Conforme ressalta Alós (2017, p. 102), "é necessário ter em mente que, mais do que produzir fruição e resultados estéticos, a literatura (assim como todas as representações culturais) produz valores, ideias, sentimentos e estruturas de pensamento que interferem diretamente na vida social".

Se até então Alós deteve-se a investigar as intersecções entre gênero, raça e classe social em obras de autoria feminina, a partir do capítulo cinco, considerado como o divisor de águas da obra, o autor passa a abordar também outra categoria: a sexualidade. "Prolegomena queer: gênero e sexualidade nos estudos literários" utiliza-se dos estudos queer no campo dos estudos literários e da literatura comparada, na tentativa de responder aos questionamentos sobre como a investigação nessa área pode apropriar-se das reflexões propostas no âmbito dos estudos queer. Nesse sentido, o capítulo apresenta, primeiramente, a visão do autor a respeito da categoria sexo, ancorada profundamente nas concepções de Michel Foucault (1994), na obra História da sexualidade, a qual expõe as dinâmicas que envolvem o sexo e o poder nas sociedades ocidentais, demonstrando como o primeiro configura-se como um constructo discursivo marcado historicamente - e não como uma constante universal.

Ao longo da história, houve distintas formas de conceituações, nomeações e tentativas de regulação do sexo, mas, em meio às variações, a necessidade de discursivização do sexo manteve-se como uma constante. Para Foucault (1994), reduzir o sexo ao nível da linguagem constituía-se como uma forma de dominá-lo e controlar sua livre circulação a partir do discurso. Esse processo gerou uma espécie de policiamento do sexo, que, no entanto, não deve ser confundido com sua interdição ou repressão, uma vez que a ampla disseminação desses discursos (amparados em conhecimentos advindos da biologia, do direito, da psiquiatria, da 
psicologia, da igreja, etc.) promoveu sua nomeação e classificação, facilitando, por sua vez, a administração, a regulação e o controle da sexualidade pelo poder estatal.

Nesse sentido, as sexualidades consideradas periféricas - em relação ao padrão "normal" ou "natural" construído pelos discursos dessas instituições - davam origem aos sujeitos considerados "anormais" ou "perversos" nessas sociedades, particularmente, os homossexuais. Com o intuito de investigar as possibilidades das teorizações atuais sobre gênero, sexo e sexualidade, amparando-se também na obra de Judith Butler (1999), nesse capítulo, Alós discorre sobre as produções de dois autores: o escritor argentino Manuel Puig e o romance $E l$ beso de la mujer araña; e o escritor brasileiro Caio Fernando Abreu e o romance Onde andará Dulce Veiga? - ambas relacionadas com a temática das sexualidades dissonantes.

De acordo com Alós, compreender as categorias de sexo e gênero como constructos performativos implica entender que não existe uma essência universal que possa definir o que se constitui como masculino ou feminino, assim como o que se identifica como homossexualidade, bissexualidade ou heterossexualidade. Dessa forma, quando o autor propõe o exercício de pensar identidades sexuais menos estáveis e mais fluidas, "a questão pertinente não é mais a definição das identidades homo ou heterossexuais, identidades gendradas de masculinidade ou feminilidade, mas sim a investigação em torno dos interesses aos quais serve o engessamento das identidades, dos gêneros $e$ dos afetos" (Alós, 2017, p. 132, grifo nosso).

Por fim, o último capítulo da obra de Alós ("Heterotopias do desassossego: literatura e subversão sexual na América Latina") apresenta uma leitura panorâmica de produções literárias latino-americanas, com o intuito de construir uma heterotopologia ${ }^{3}$ - aqui entendida como "estudo dos espaços outros, ou dos espaços de alteridade" (Alós, 2017, p. 197, grifos do autor) visando a identificação de semelhanças e diferenças na estruturação das paisagens heterotópicas dos romances contemporâneos em diferentes países da América Latina. Este estudo, que encerra o conjunto de ensaios, vai ao encontro dos anteriores e realiza um fechamento fundamental, na medida em que propõe uma avaliação do impacto e das consequências das diversas ficções e romances políticos analisados no que se refere a uma maior representatividade de gêneros, afetos e desejos e à subversão dos regimes baseados em padrões heteronormativos e em uma heterossexualidade compulsória. ${ }^{4}$

Simultaneamente, o capítulo final - e o próprio volume, como um todo - assume seu compromisso em visibilizar uma maior amplitude de vozes com origens em sujeitos considerados como alteridade nessas sociedades, posicionamento adotado por Alós e particularmente fundamental em tempos em que a intolerância e o pensamento reacionário têm crescido assustadoramente. Nesse sentido, não se almeja um apagamento das diferenças em busca de uma suposta homogeneidade, mas, sim, reivindica-se o reconhecimento e a representação da heterogeneidade, a visibilidade dessas vozes e saberes, de forma a construir discussões e reflexões que possam, mais do que pensar, buscar maneiras de interferir no contexto social, político e cultural atual.

\section{Referências}

ABREU, Caio Fernando (1990). Onde andará Dulce Veiga? São Paulo: Companhia das Letras.

\footnotetext{
${ }^{3}$ Para compreender o uso do termo heterotopologia adotado pelo autor, é necessário rememorar a categoria cunhada por Foucault: heterotopia. Heterotopia, de acordo com Foucault, refere-se a espaços outros, um lugar em que as convenções, regramentos e a ordem social são invertidos, contestados, suspensos. Outra forma de definição pode ser observada através da explicação de Alós (2017, p. 197): "se a utopia é um não lugar, a heterotopia pode ser entendida, ao menos inicialmente, como uma “utopia realizada"”.

${ }^{4}$ Essa expressão foi cunhada pela feminista Adrienne Rich, em 1980, particularmente ao analisar a experiência lésbica, abordando a ideia de heterossexualidade como uma instituição política responsável por retirar o poder das mulheres a partir de diversos mecanismos construídos historicamente.
} 
ALÓS, Anselmo Peres (2013). A letra, o corpo e o desejo: masculinidades subversivas no romance latinoamericano. Florianópolis: Mulheres.

ALÓS, Anselmo Peres (2017). Leituras a contrapelo da narrativa brasileira: redes intertextuais de gênero, raça e sexualidade. Santa Maria: PPGL/UFSM.

ALÓS, Anselmo Peres (Org.) (2017). Poéticas da masculinidade em ruínas: o amor em tempos de AIDS. Santa Maria: PPGL/UFSM.

ALÓS, Anselmo Peres; FELIPPE, Renata Farias de; SOUTO, Andrea do Roccio (Org.) (2017). Figurações do imaginário cinematográfico na contemporaneidade. Santa Maria: PPGL/UFSM.

BURGOS-DEBRAY, Elizabeth; MENCHÚ, Rigoberta (1991). Me llamo Rigoberta Menchú y así me nació la consciencia. La Habana: Casa de las Américas.

BUTLER, Judith (1999). Gender trouble: feminism and the subversion of identity. 10. ed. London: Routledge. FOUCAULT, Michel (1994). História da sexualidade: a vontade de saber. 7. ed. Rio de Janeiro: Graal.

JESUS, Carolina Maria de (2001). Quarto de despejo: diário de uma favelada. São Paulo: Ática.

PUIG, Manuel (1994). El beso de la mujer araña. New York: Vintage Books.

RANDALL, Margaret (1992). ¿Que és y cómo se hace un testimonio? In: BEVERLY, John; ACHUGAR, Hugo (Ed.). La voz del otro: testimonio, subalternidad y verdad narrativa. Lima-Berkeley: Latinoamericana.

RICH, Adrienne (2010). Heterossexualidade compulsória e existência lésbica. Bagoas, Natal, v. 4, n. 5, p. 17-44.

SCOTT, Joan (1990). Gênero: uma categoria útil de análise histórica. Educação \& realidade, Porto Alegre, v. 16, n. 2, p. 71-99. 